\title{
Design of Printed Dipole Array for Omnidirectional Radiation Pattern
}

\author{
Jean-Marie Floc'h \\ IETR, INSA Rennes, Rennes, France \\ Email: jean-marie.floch@insa-rennes.fr
}

How to cite this paper: Floc'h, J.-M (2019) Design of Printed Dipole Array for Omnidirectional Radiation Pattern. Wireless Engineering and Technology, 10, 19-33. https://doi.org/10.4236/wet.2019.102002

Received: October 1, 2018

Accepted: March 3, 2019

Published: March 6, 2019

Copyright $\odot 2019$ by author(s) and Scientific Research Publishing Inc. This work is licensed under the Creative Commons Attribution International License (CC BY 4.0).

http://creativecommons.org/licenses/by/4.0/

\begin{abstract}
In this paper, we describe 2 kinds of printed dipole arrays and compare the performances of these arrays in term of reflexion coefficient, radiation pattern and dimensions. It is interesting to design array in order to obtain better performances in term of omnidirectional radiation pattern in comparison with single element. We choose this elementary source in order to obtain compact array with good performances. These antenna arrays are designed to have omnidirectional radiation pattern with horizontal polarization. We present an application dedicated to compact base station in the last section.
\end{abstract}

\section{Keywords}

Printed Dipole, Dipole Array, Omnidirectionel Radiation Pattern, Horizontal Polarization

\section{Introduction}

Omnidirectional antennas are very interesting in many applications such as communication systems, base station and sensors [1]-[6]. Specific applications for communication systems could be in rotating structure like airplane engine, wheels and rotating machines.

In the first section, we describe the chosen single element choosing for the arrays. After we present two types of printed dipole arrays (3-dipole array and 4-dipole array), the goal is to obtain compact array with good performances in term of radiation pattern and Omni directionality. We then compare the performances of the two arrays in term of gain and efficiency. In the last section, we present an application for base station for communication systems with results in simulation and measurements for the 3-dipole array and simulation for the 4-dipole array. For all the radiation measurements, gain and efficiency, we use a Stargate 32 from SATIMO. 
The elementary source, a printed dipole, is presented in the next section.

\section{Elementary Source}

The chosen elementary dipole is described in Figure 1.

The dipole antenna consists of two arms printed on opposite sides of the substrate with a total length around $\lambda / 2$. The distance between the arms and the ground plane is around $\lambda / 4$. This structure was simulated and optimized using the electromagnetic simulator HFSS for a frequency of $3 \mathrm{GHz}$ with as shown in Figure 2.

The optimized dipole antenna radiates at $3 \mathrm{GHz}$ as presented in Figure 1. The simulated maximum gains are respectively $2.7 \mathrm{dBi}$ and $2.4 \mathrm{dBi}$ in measurement as we can see in Figure 3 and Figure 4. We note a good agreement between measurement and simulation for both reflection coefficient and radiation pattern.

We note also that don't have good omnidirectional radiation patterns in the horizontal polarization (Figure 3 ).

We obtain a ripple of $\pm 0.8 \mathrm{dBi}$ in the xoz plane in simulation and much more in measurements.
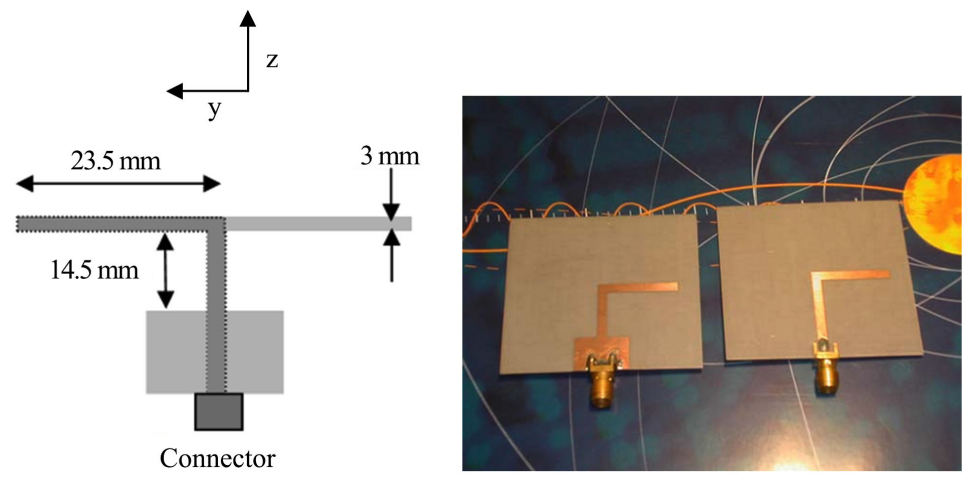

Figure 1. Single printed dipole.

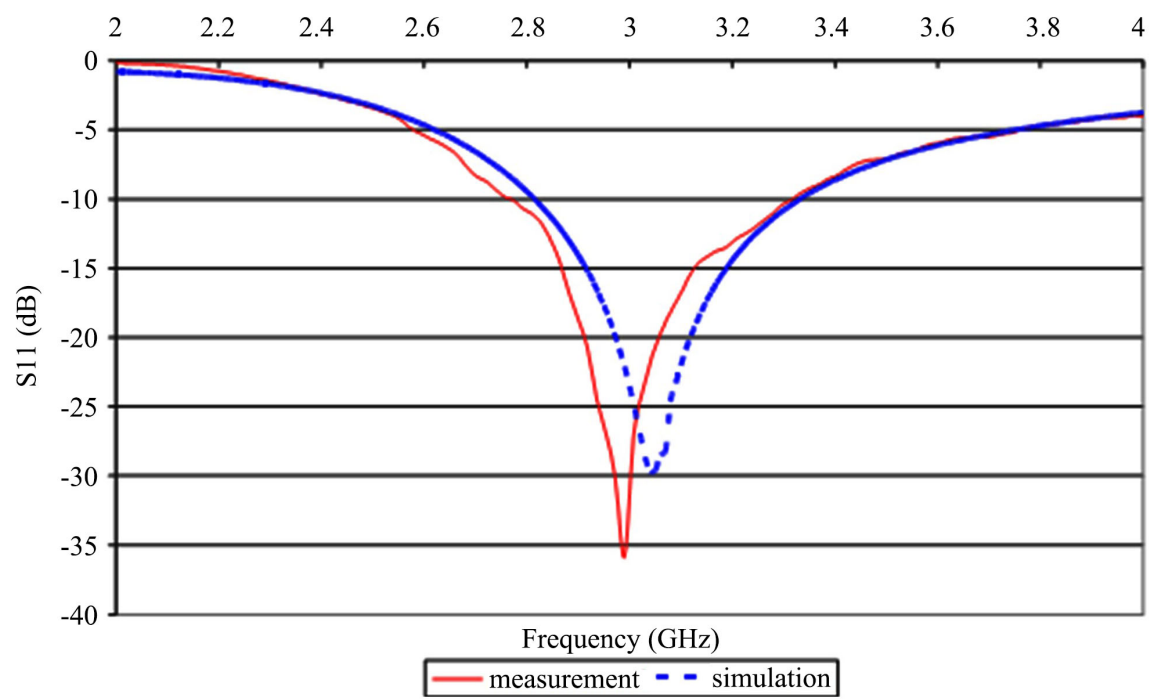

Figure 2. Measured and simulated $\mathrm{S}_{11}$ for elementary dipole. 


\section{Array of 3 Printed Dipoles}

Dipole arrays are interesting if we want better performances in term of omnidirectionnality and gain. We compare two potential arrays to be capable to respond to this functionality.
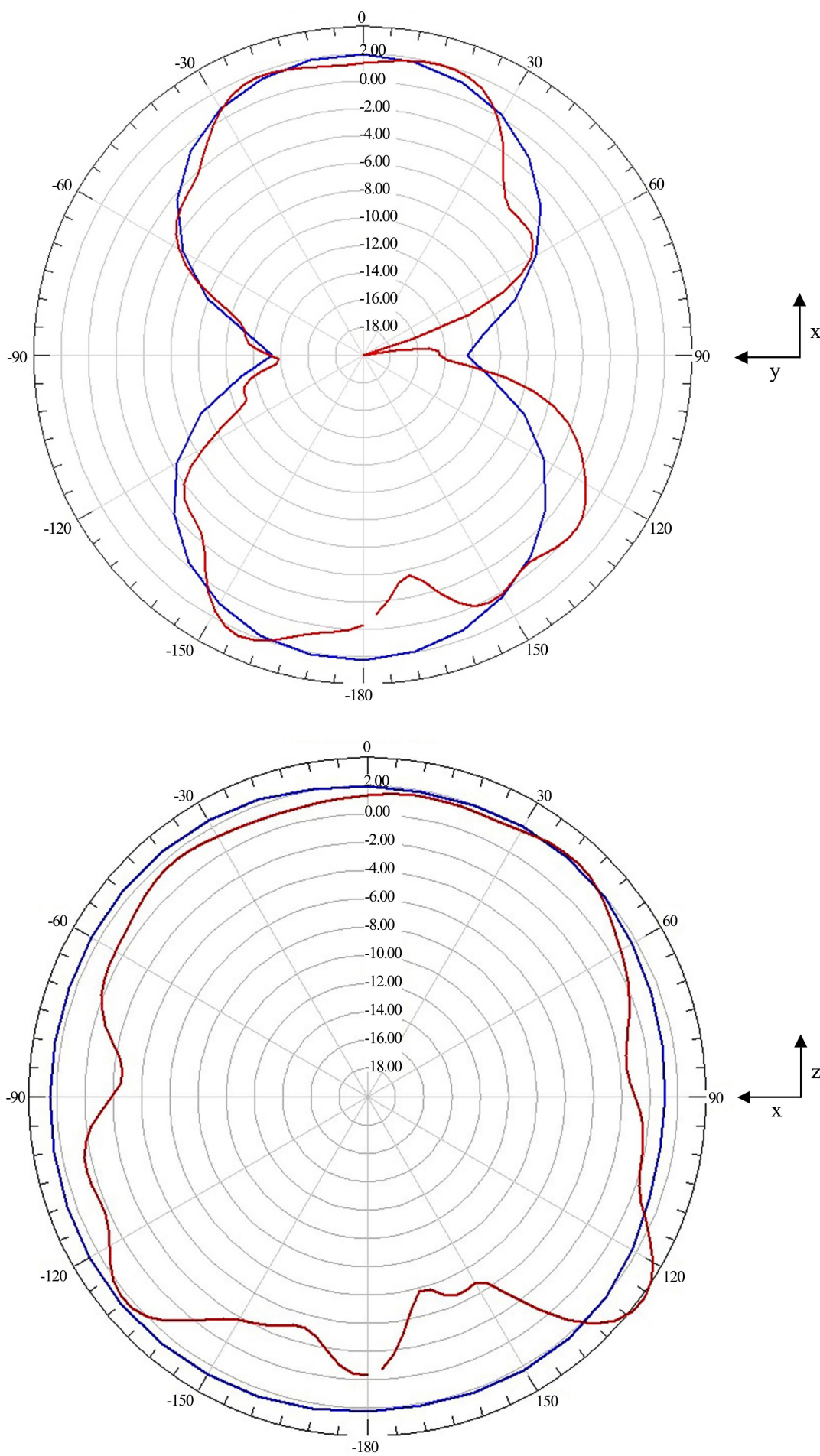

Figure 3. Simulated and measured gain in xoy planeand in xoz plane at $3 \mathrm{GHz}$ (simulation in red and measurements in blue). 


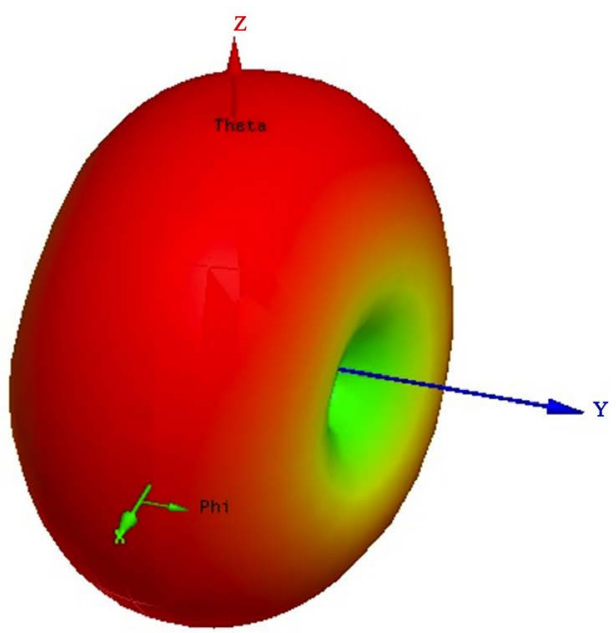

(a)

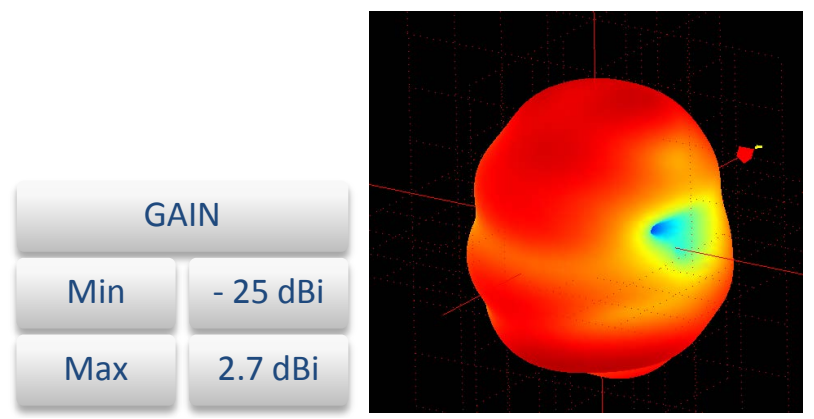

(b)

Figure 4. 3D radiation patterns at $3 \mathrm{GHz}$ : (a) Simulation and (b) measurement.

We present this first array in Figure 5. It consist of a circular network of 3 printed dipoles positioned every $120^{\circ}$. The diameter of the array is $60 \mathrm{~mm}$, the substrate is a Teflon-glass with 2.2 permittivity and a $0.8 \mathrm{~mm}$ thickness. The feeding of the proposed array is realized in its center with a SMA connector. The frequency design is around $3 \mathrm{GHz}$. The dimensions of the dipole are the same that the last section. Like the elementary dipole, the square ground plane where the connector is welded is placed at around $\lambda / 4$.

Figure 6 presents the reflection coefficient for simulation (blue) and measurements (red). The 3 dipole array radiates at $3 \mathrm{GHz}$ as predicted. The bandwidth of this array is $230 \mathrm{MHz}$ between 2.85 and $3.08 \mathrm{GHz}$ at $\mathrm{S} 11$ less than -10 dB.

The simulated and measured 3D radiation paterns $\mathrm{E}$ total are presented in Figure 7. The axis is $\mathrm{z}$ in red, $\mathrm{x}$ in green and $\mathrm{y}$ in blue. The maximum gain is 1.7 $\mathrm{dBi}$ for simulation and $3 \mathrm{dBi}$ for measurements. The measured efficiency at 3 $\mathrm{GHz}$ is $85 \%$.

We present in Figure 8 the radiation patterns at $3 \mathrm{GHz}$ for the $\mathrm{XOZ}$ and $\mathrm{XOY}$ planes. Simulated result is in blue and measured one in red. In the XOY plane, the ripple on the radiation pattern is around $\pm 1.1 \mathrm{dBi}$.

We note a good agreement between simulation and measurements. 


\section{Dipole Array}

The proposed circular 4 dipole array is shown in Figure 9.

In this case, the circular network of 4 printed dipoles are positioned every $90^{\circ}$. We use the same substrate and the same feeding connector as the 3 dipole array. The dimensions of the dipole are also the same. We place the dipoles at $\lambda / 4$ from the square ground plane like the 3 dipole array. The diameter of this antenna is also $60 \mathrm{~mm}$. The frequency design of the array is around $3 \mathrm{GHz}$ as it can be concluded from the reflection coefficient of the array presented in Figure 10. The measured bandwidth of the array is $190 \mathrm{MHz}$ between 2.7 and $2.89 \mathrm{GHz}$. We note a reduction of the bandwidth in comparison with the 3 dipole array.

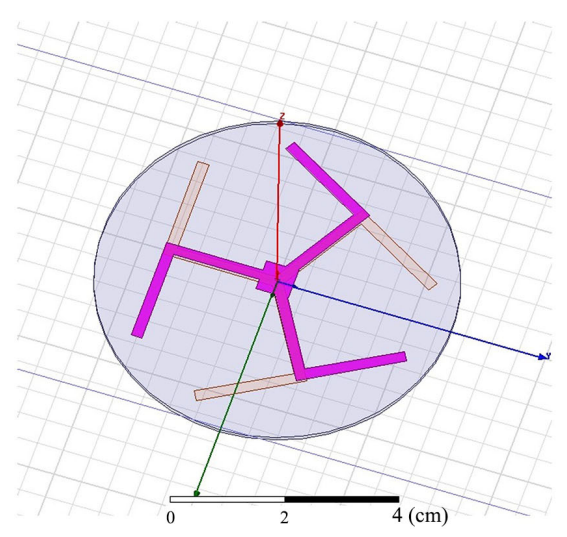

(a)

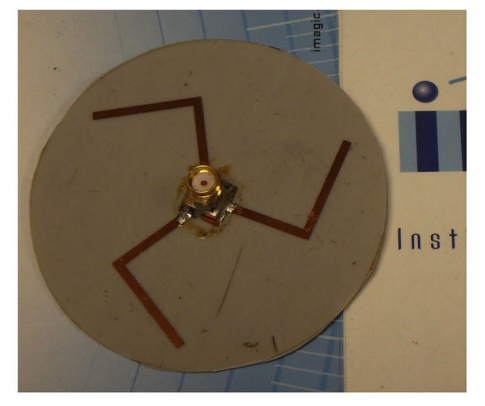

(b)

Figure 5. 3 dipole array: (a) Simulated array and (b) Prototyped structure.

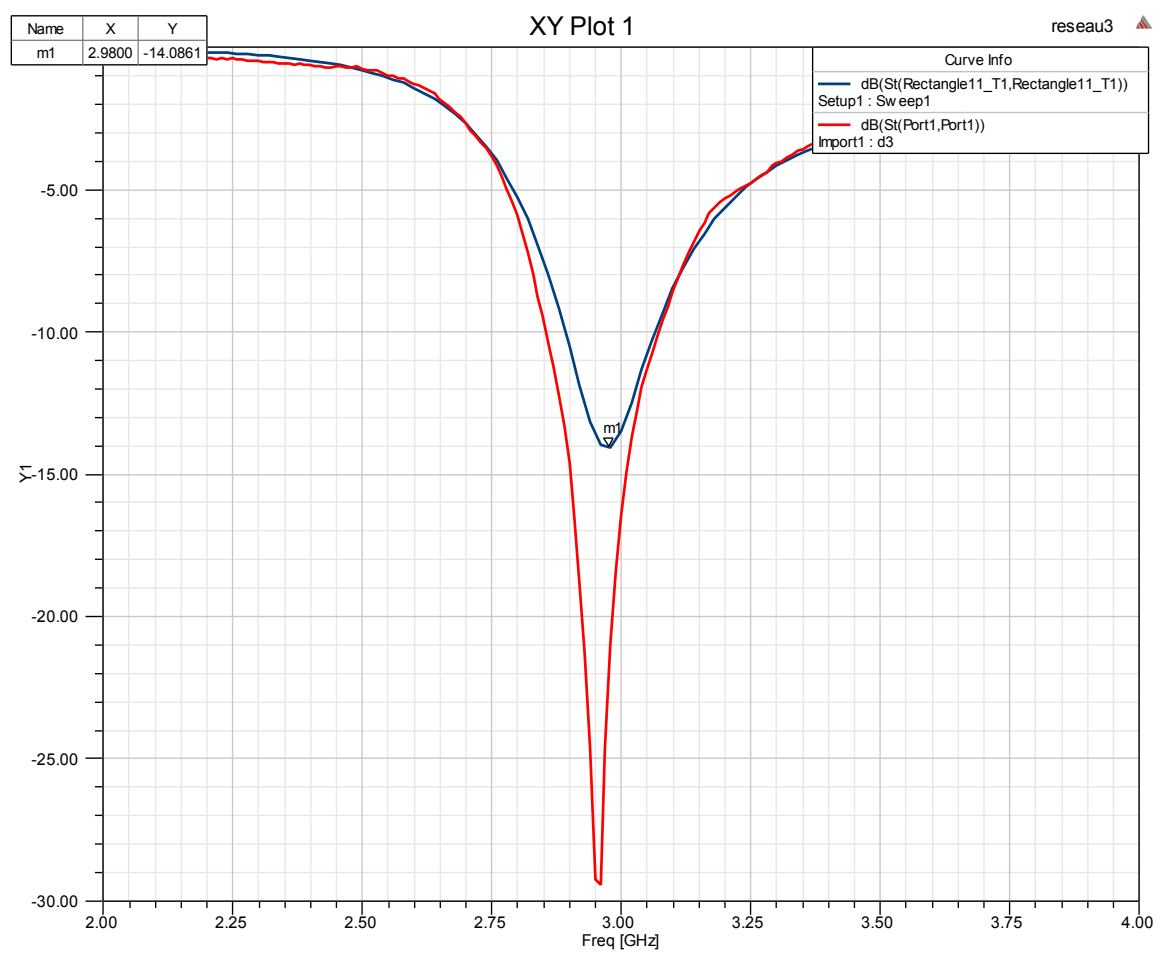

Figure 6. Reflection coefficient of the 3 dipole array. 

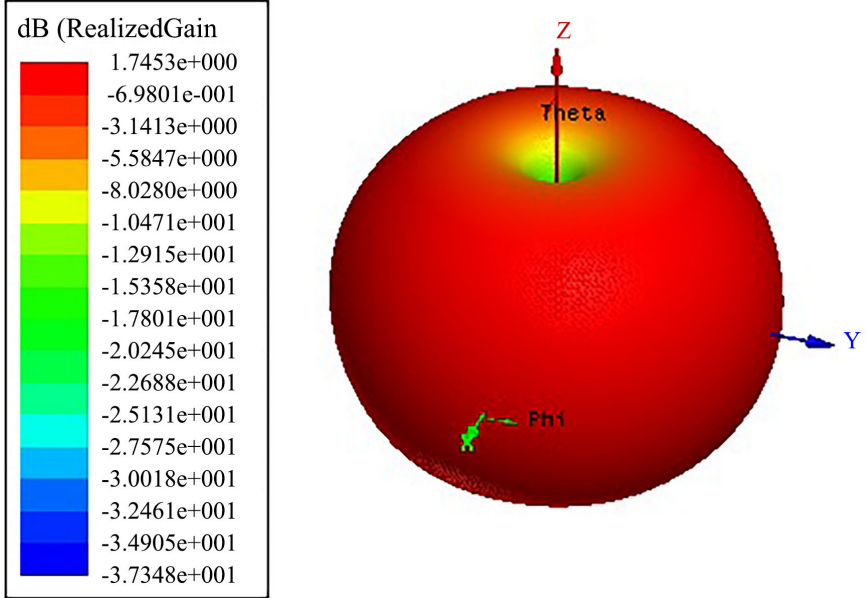

(a)

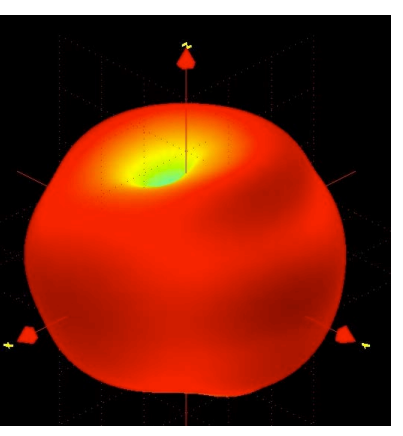

(b)

Figure 7. 3D radiation patterns at $3 \mathrm{GHz}$ (a) Simulation and (b) Measurement.

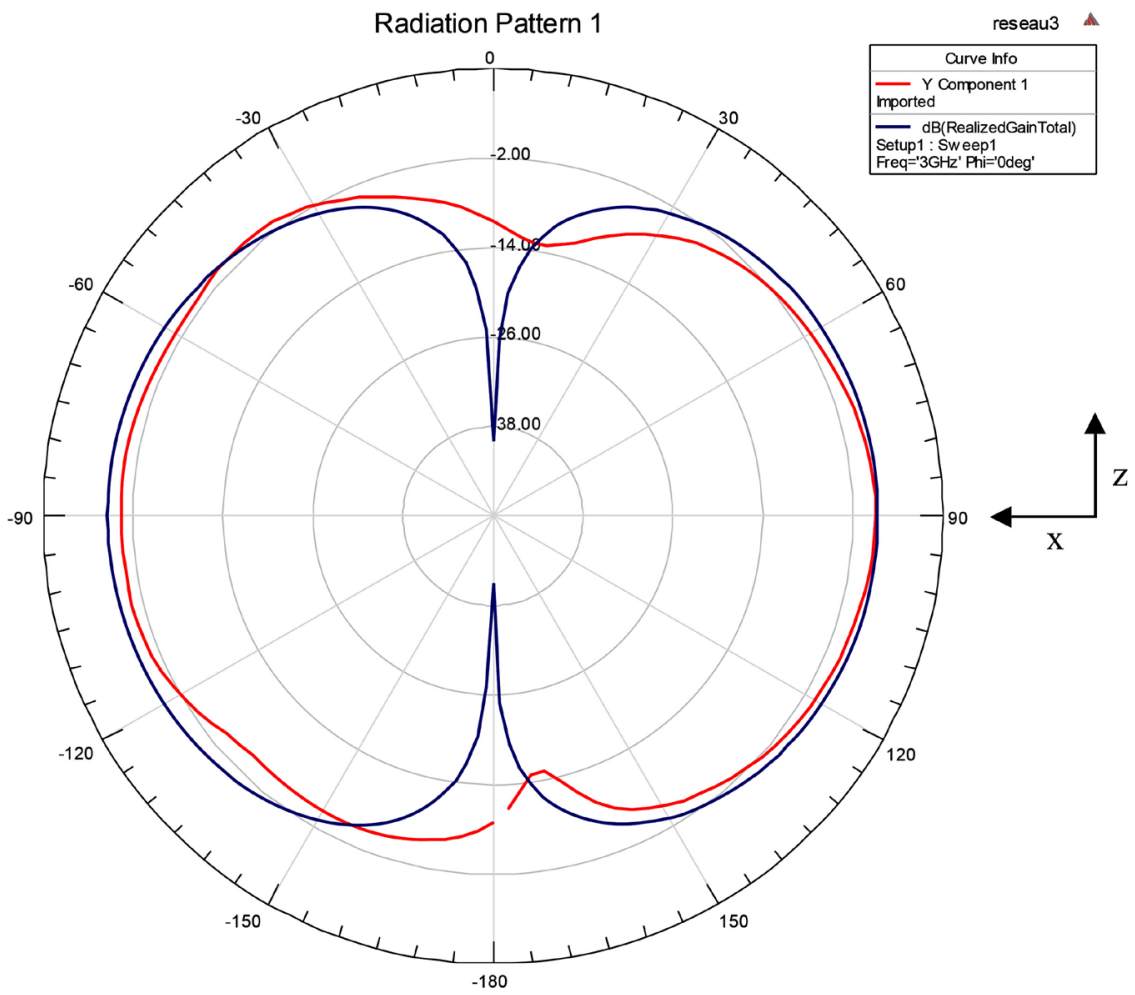




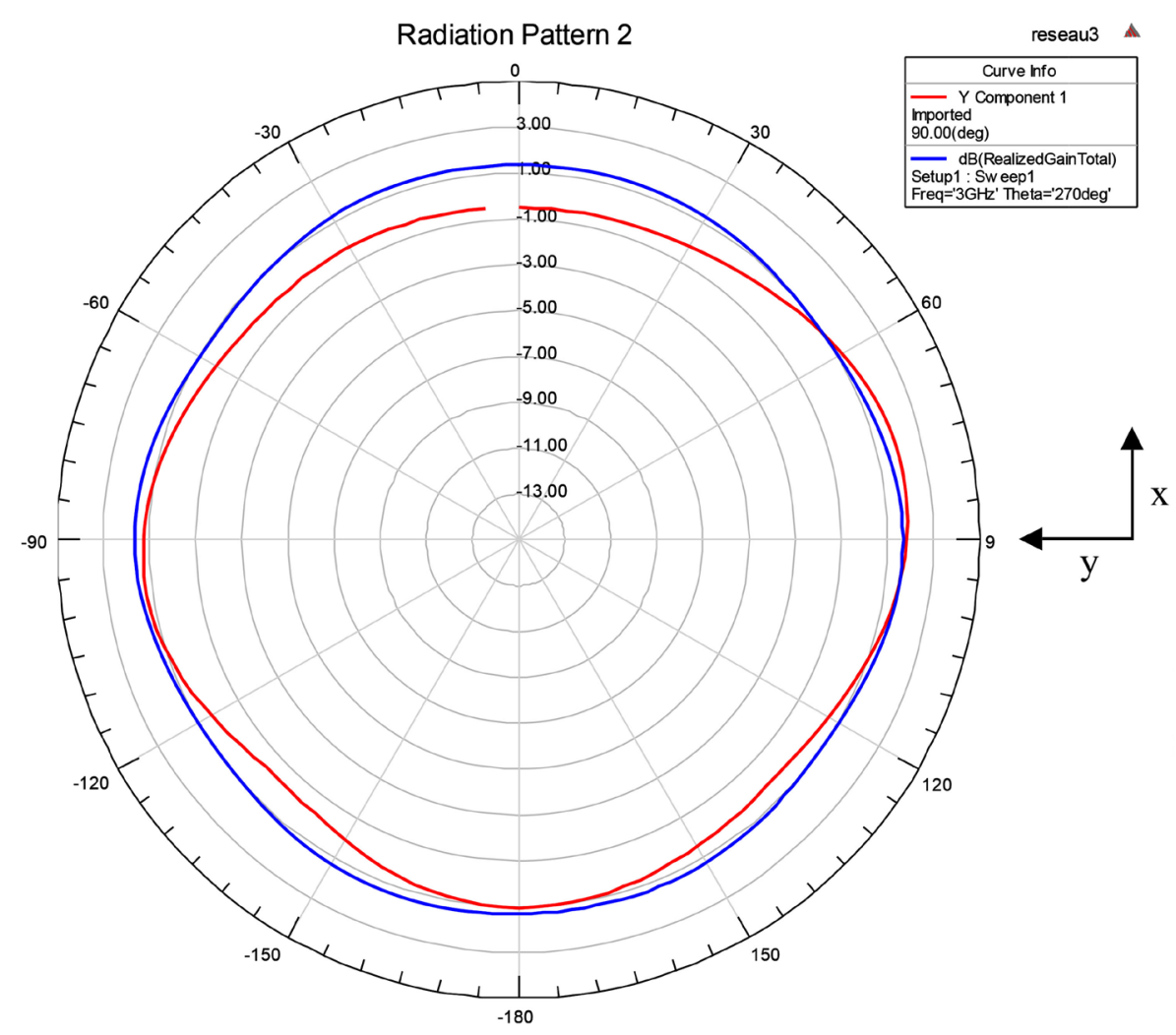

Figure 8. Radiation patterns in xoz and xoy plane at $3 \mathrm{GHz}$. Simulation in blue and measurement in red.

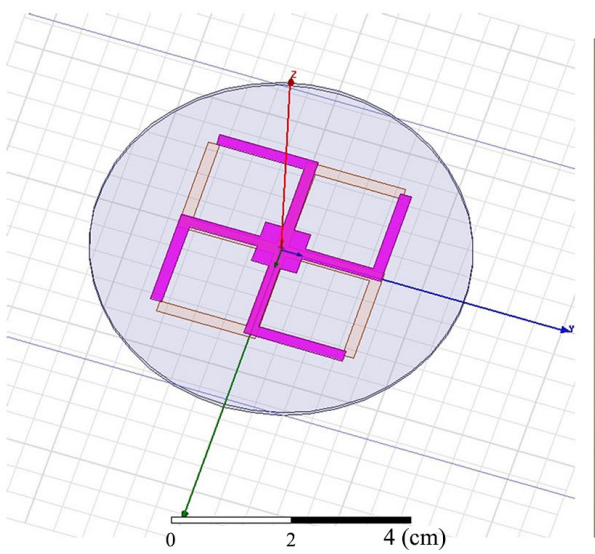

(a)

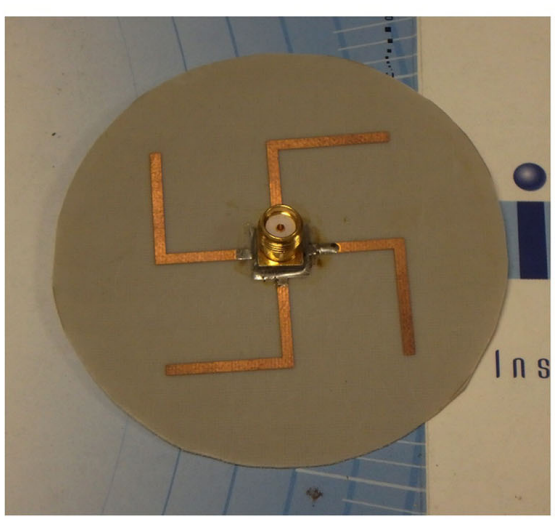

(b)

Figure 9. 4 dipole array: (a) Simulated array and (b) Prototyped structure.

The simulated and measured 3D radiation patterns are presented in Figure 11. The maximum gain measured is $1.7 \mathrm{dBi}$ at the $2.7 \mathrm{GHz}$ frequency with a value of $1.4 \mathrm{dBi}$ for simulation. The measured efficiency is $85 \%$ at the resonant frequency.

The simulated (in blue) and measured red) results of the radiation patterns in xoz and xoy planes are presented in Figure 12. In the xoy plane, the ripple on the radiation pattern is around $\pm 0.25 \mathrm{dBi}$ at $2.7 \mathrm{GHz}$. 


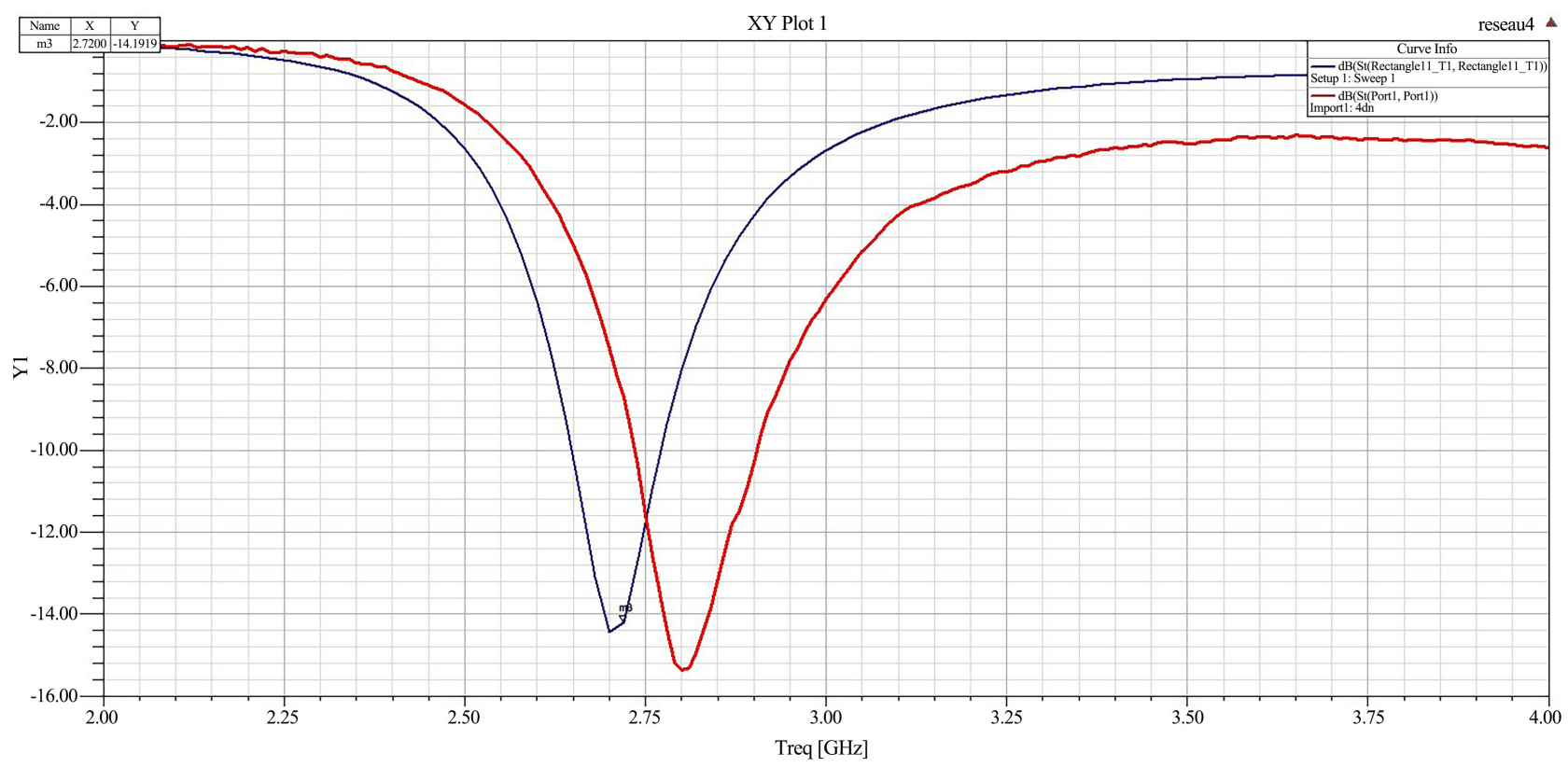

Figure 10. Reflection coefficient of the 4 dipole array: simulation in blue and measurement in red.

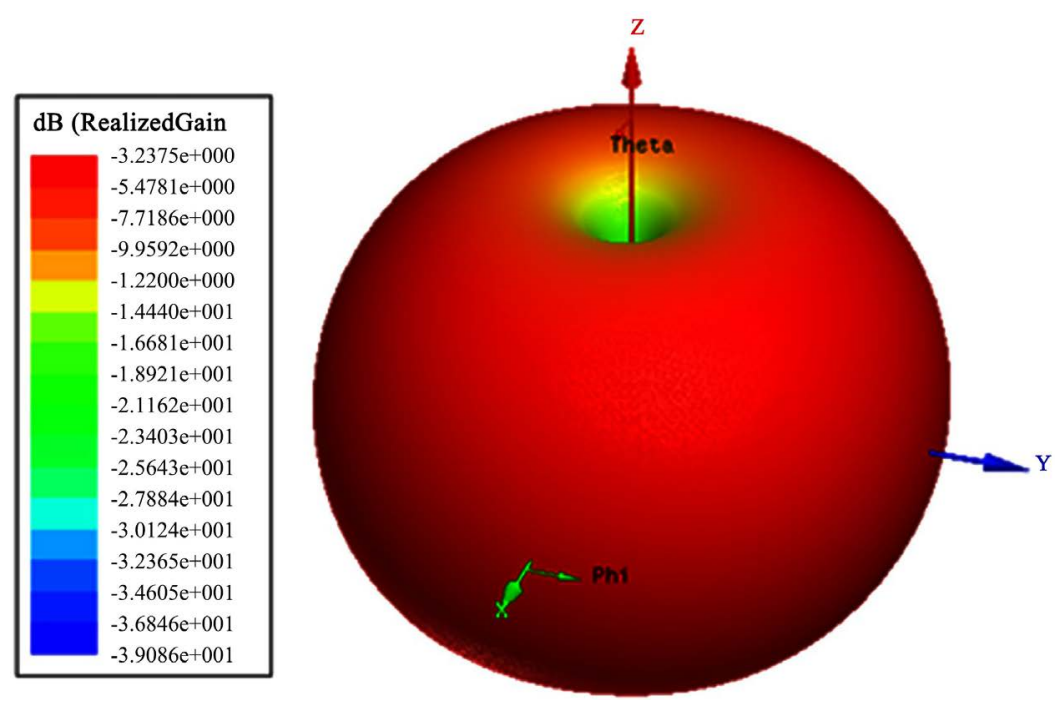

(a)

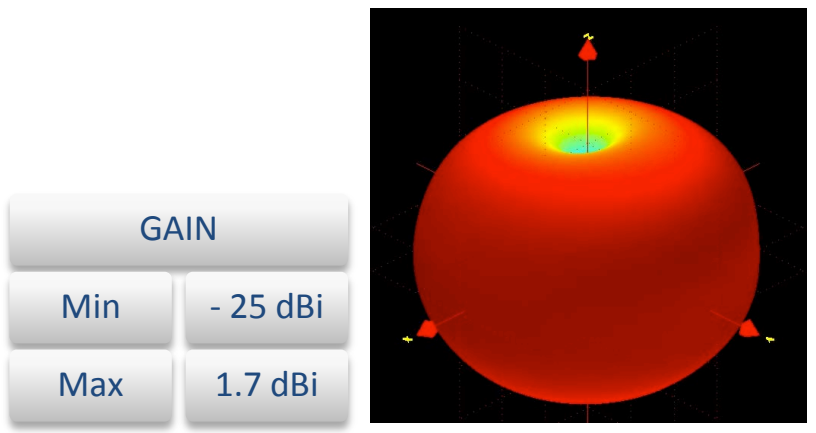

(b)

Figure 11. 3D radiation patterns for the 4 dipole array: (a) Simulation and (b) Measurement. 

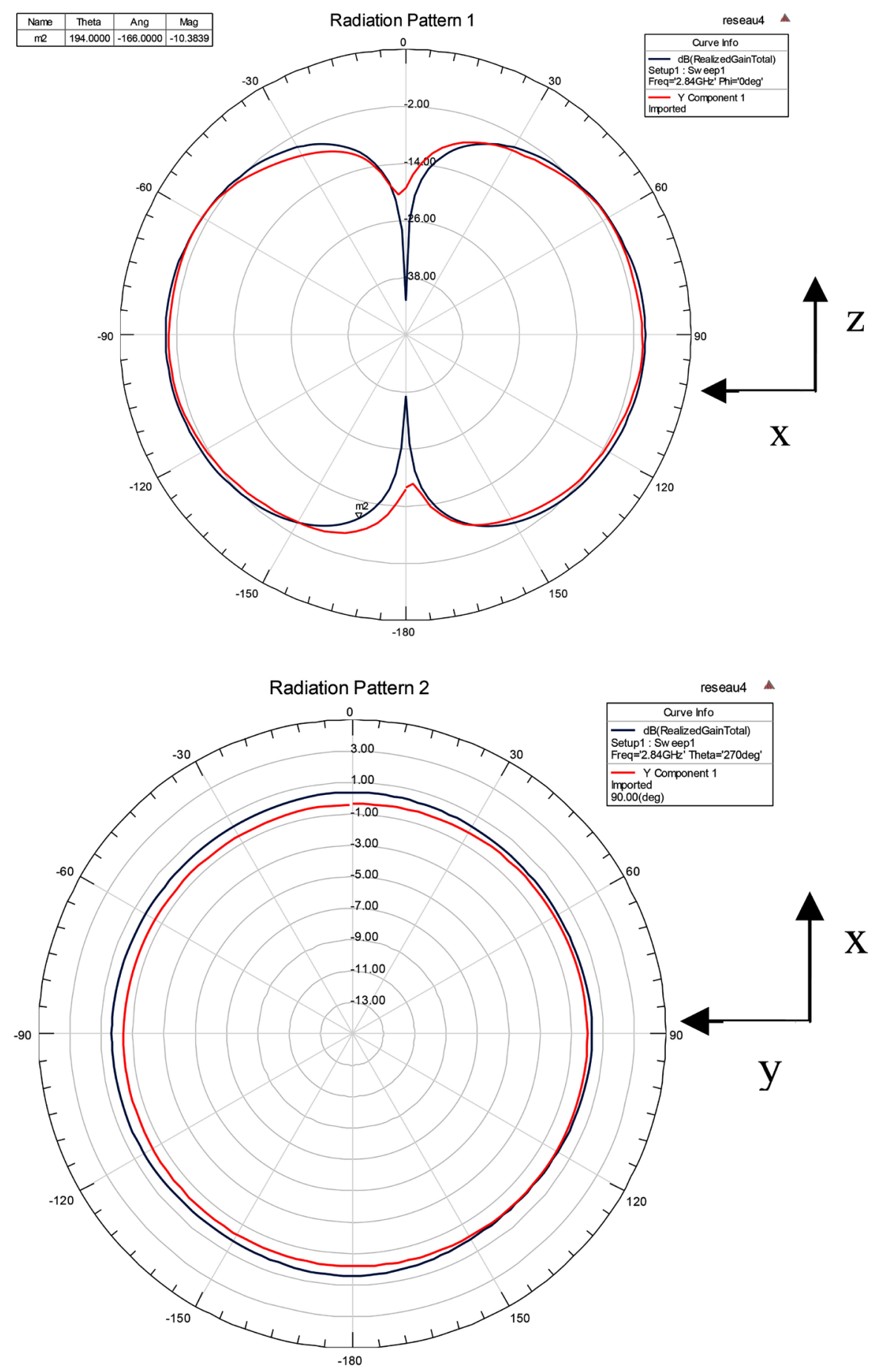

Figure 12. Radiation patterns in the xoz and xoy plane at $2.7 \mathrm{GHz}$. Simulation in blue and measurement in red.

\section{Comparison between Gain and Efficiency}

In the next section, we compare the maximum gain and the efficiency for the two dipole arrays.

We note a better gain for the 3 dipole with around $3.75 \mathrm{dBi}$ and $2 \mathrm{dBi}$ less for the 4 dipole array as shown in Figure 13. 


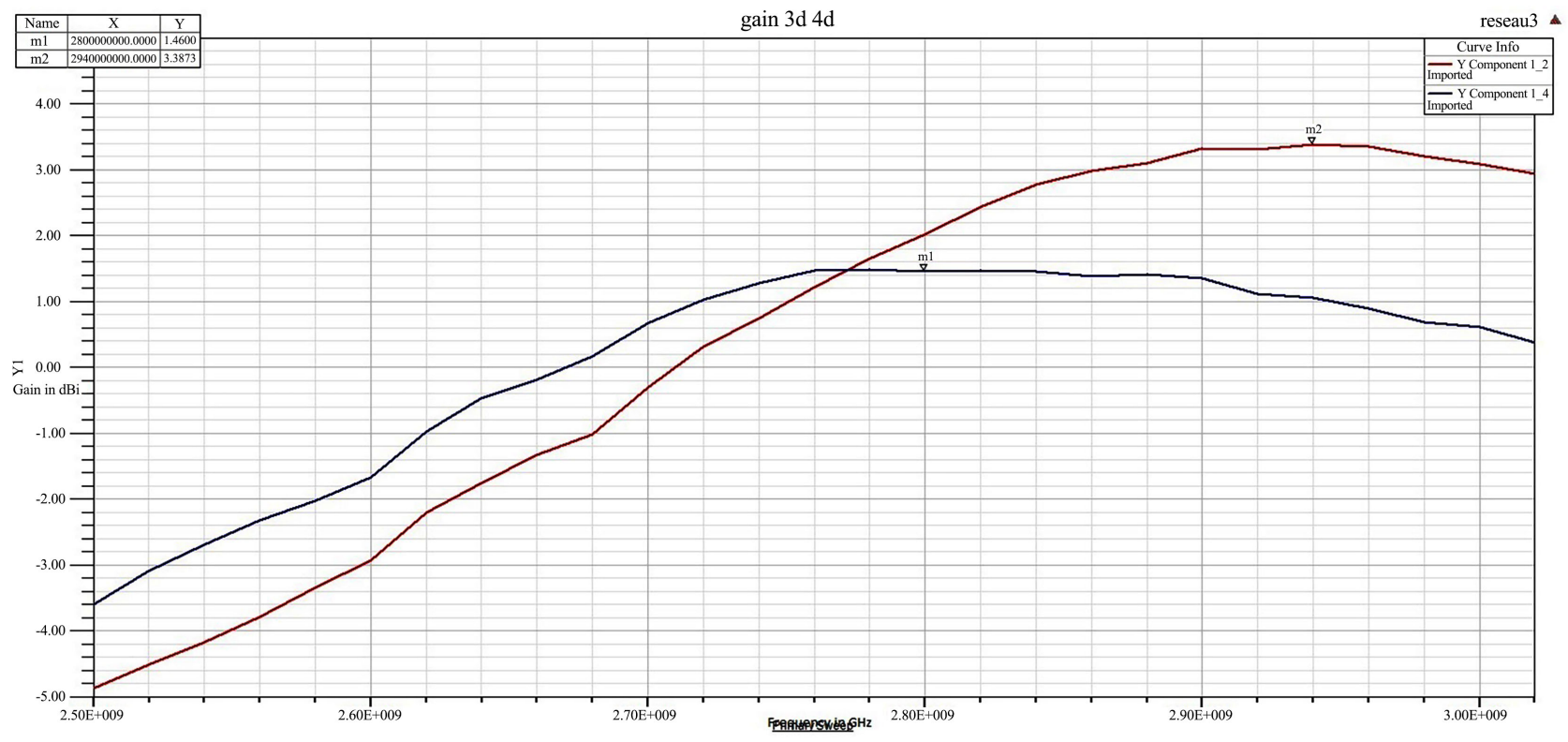

Figure 13. Maximum gain in blue for the 4 dipole array and for the 3 dipole array in red.

We note in this case efficiencyal most equal for the two arrays with a maximum efficiency around $0.88 \%$ for the 3 dipole array as shown in Figure 14.

\section{Application for Compact Base Station}

In this last section, we propose an application of the 3 dipole array for compact base station. In this application, we put a circular ground plane at $20 \mathrm{~mm}$ from the array. The radius of the ground plane is $45 \mathrm{~mm}$. we obtain a very compact base station with a $90 \mathrm{~mm}$ diameter with $20.8 \mathrm{~mm}$ thickness as shown in the next photos. It will be easy to integrate electronics and battery on the backside of the ground plane and keep a very compact base station.

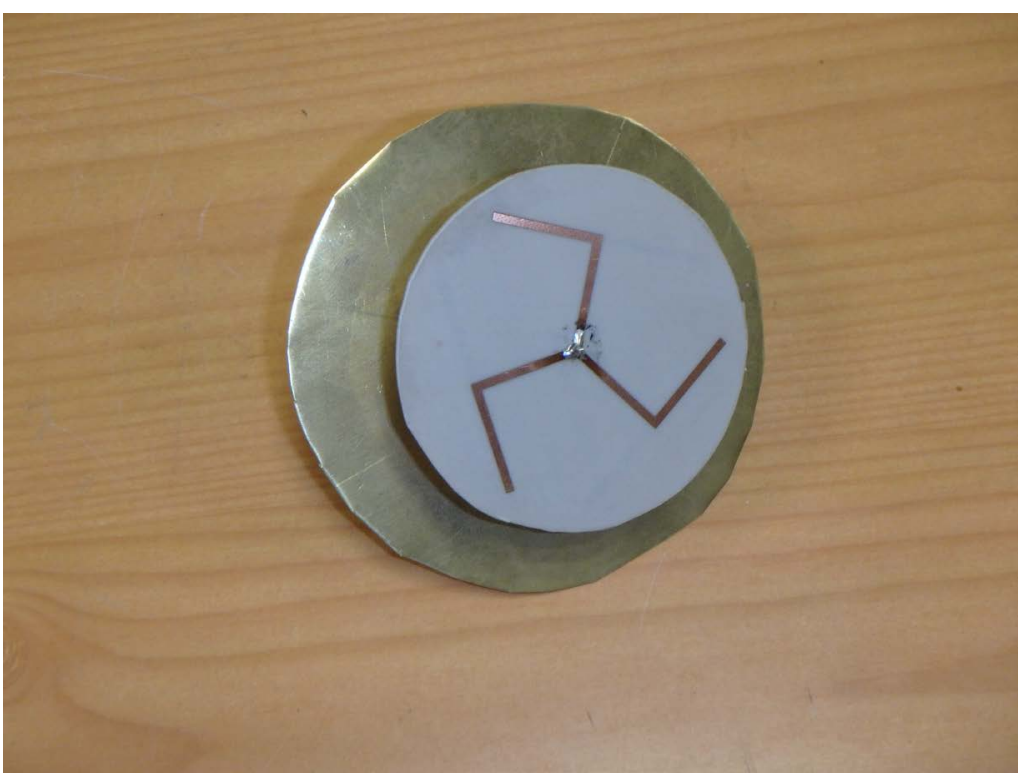




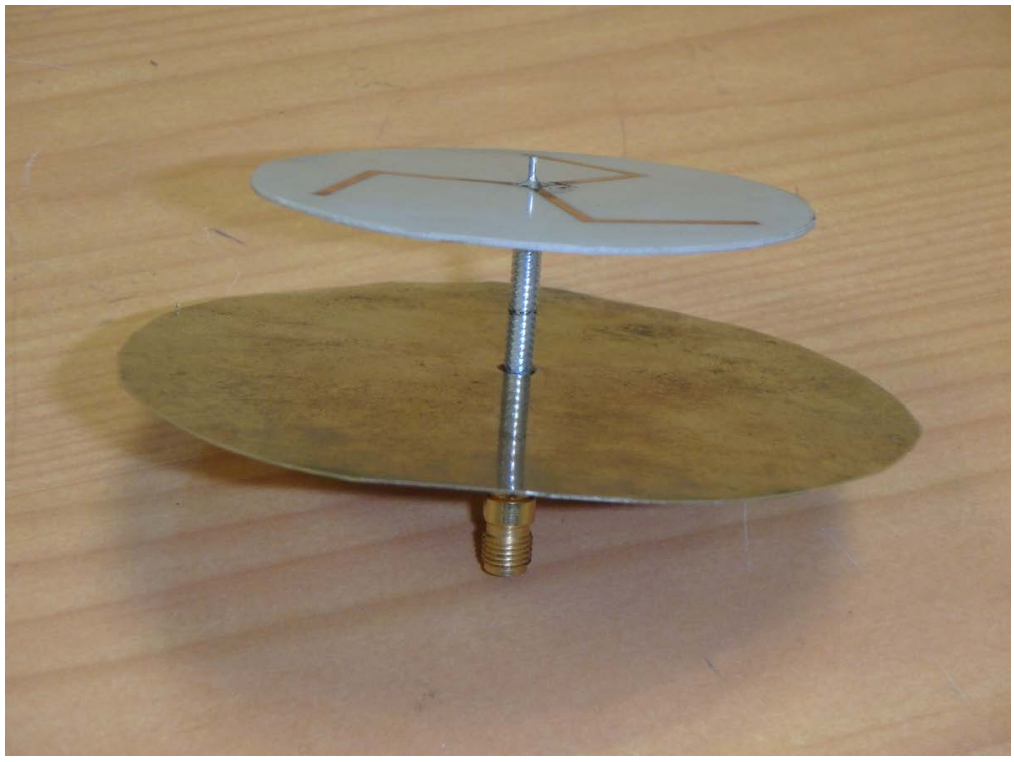

Photos of the compact base station.

The next figure presents the S11 in simulation and measurements. We note a reduce bandwidth and a sight degradation of the $S 11$ as shown in Figure 15. The degradation of S11 is due to the presence of the ground plane and the degradation increase when the distance between the ground plane and the array decrease.

We obtain a measured bandwidth for S11 less than $-6 \mathrm{~dB}$ of $190 \mathrm{MHz}$.

We obtain a ripple of $\pm 2 \mathrm{dBi}$ in the xoy plane in measurements as shown in Figure 16.

We obtain a maximum gain of $3.7 \mathrm{dBi}$ at $3 \mathrm{GHz}$ and the bandwidth at $-1 \mathrm{dBi}$ is $190 \mathrm{MHz}$ as shown in Figure 17 and Figure 18.

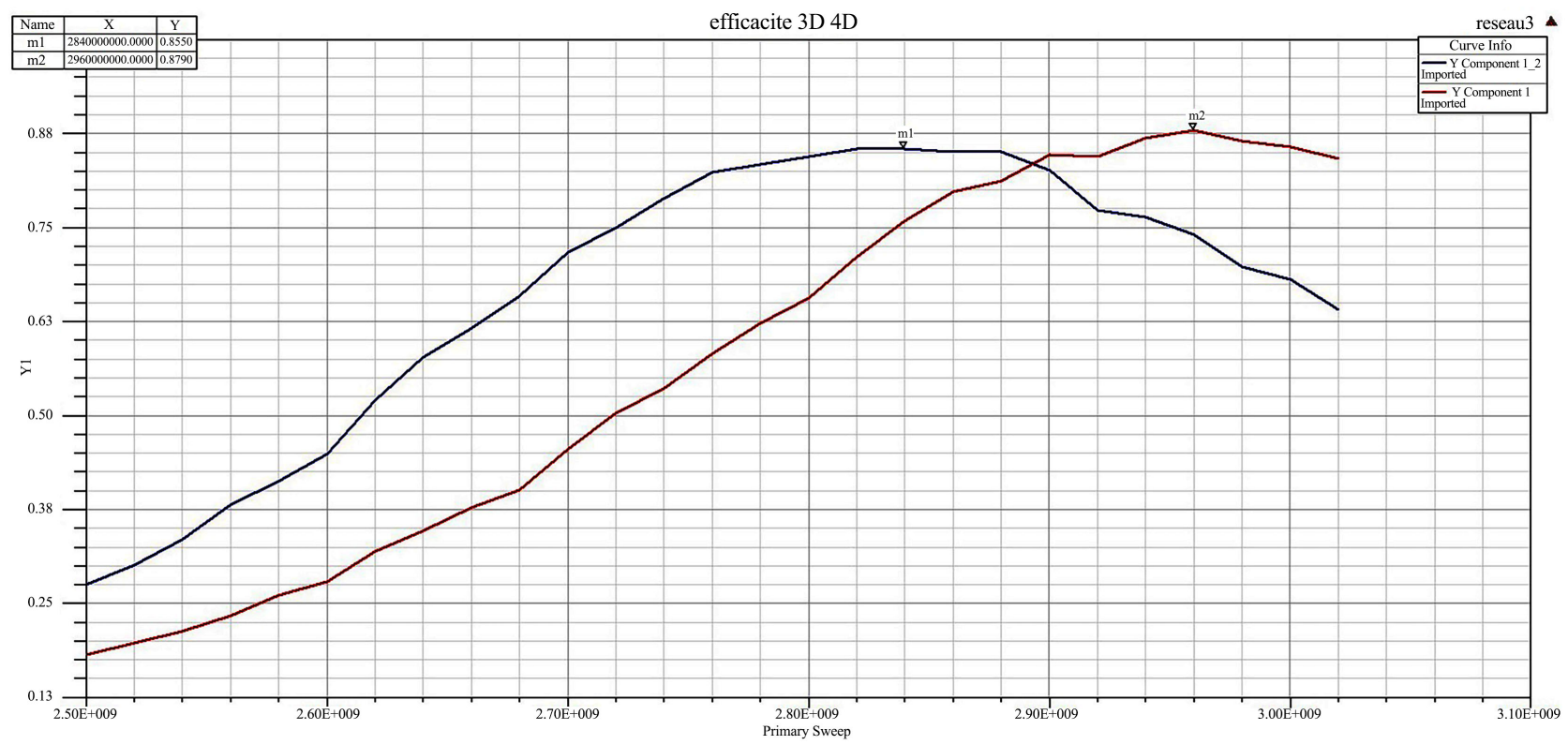

Figure 14. Efficiency in blue for the 4 dipole array and for the 3 dipole array in red. 
We obtain a maximum efficiency of $80 \%$ at the $3 \mathrm{GHz}$ frequency as shown in Figure 19. We obtain almost the same results in simulation with the 4 dipole array with ground plane but we obtain better ripple in the xoy plane $( \pm 0.15 \mathrm{dBi}$ and a maximum gain of $3 \mathrm{dBi}$ at $2.76 \mathrm{GHz}$ ) as shown in Figure 20 .

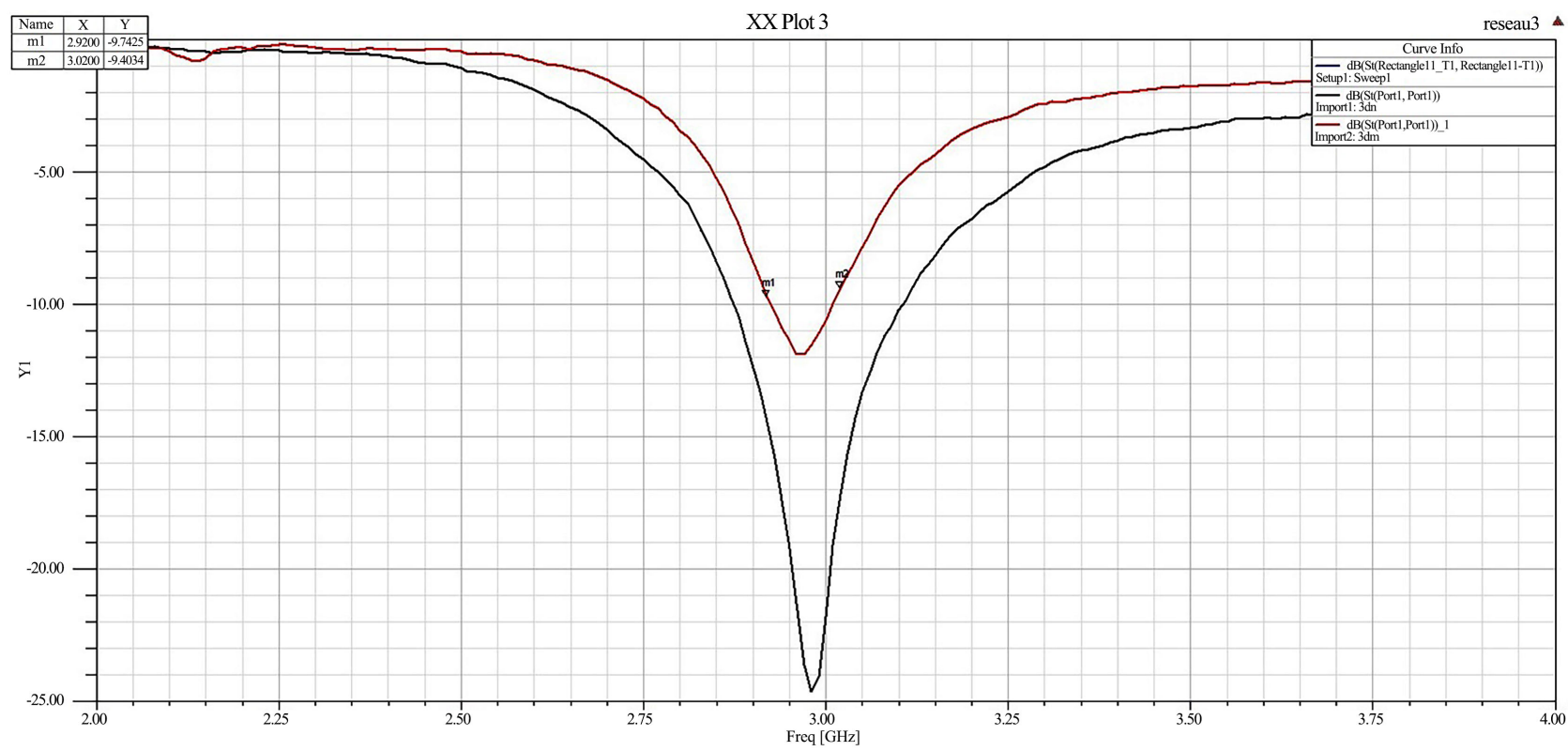

Figure 15. Reflection coefficient of the 3 dipole array with ground plane: simulation in blue and measurement in red.

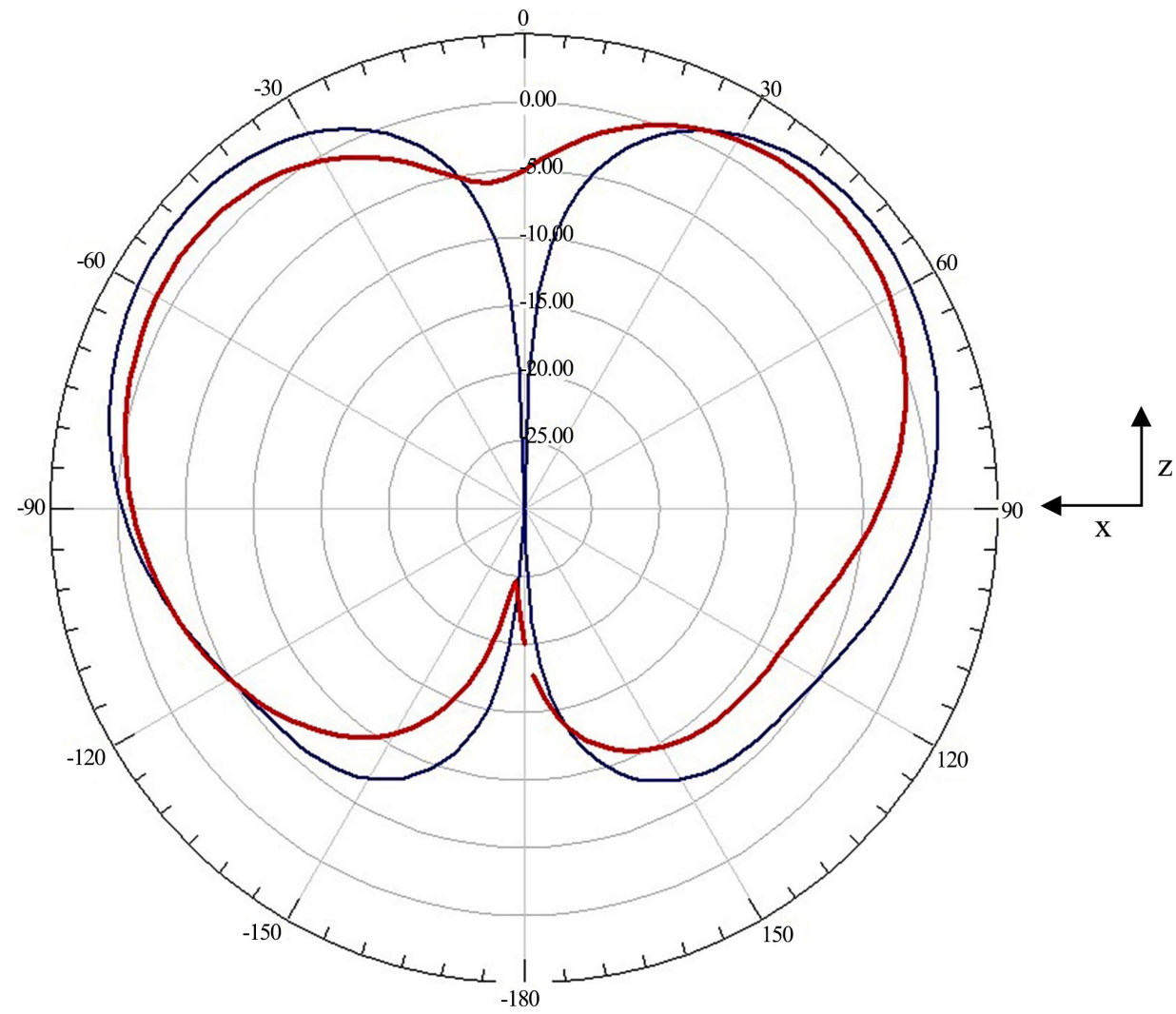




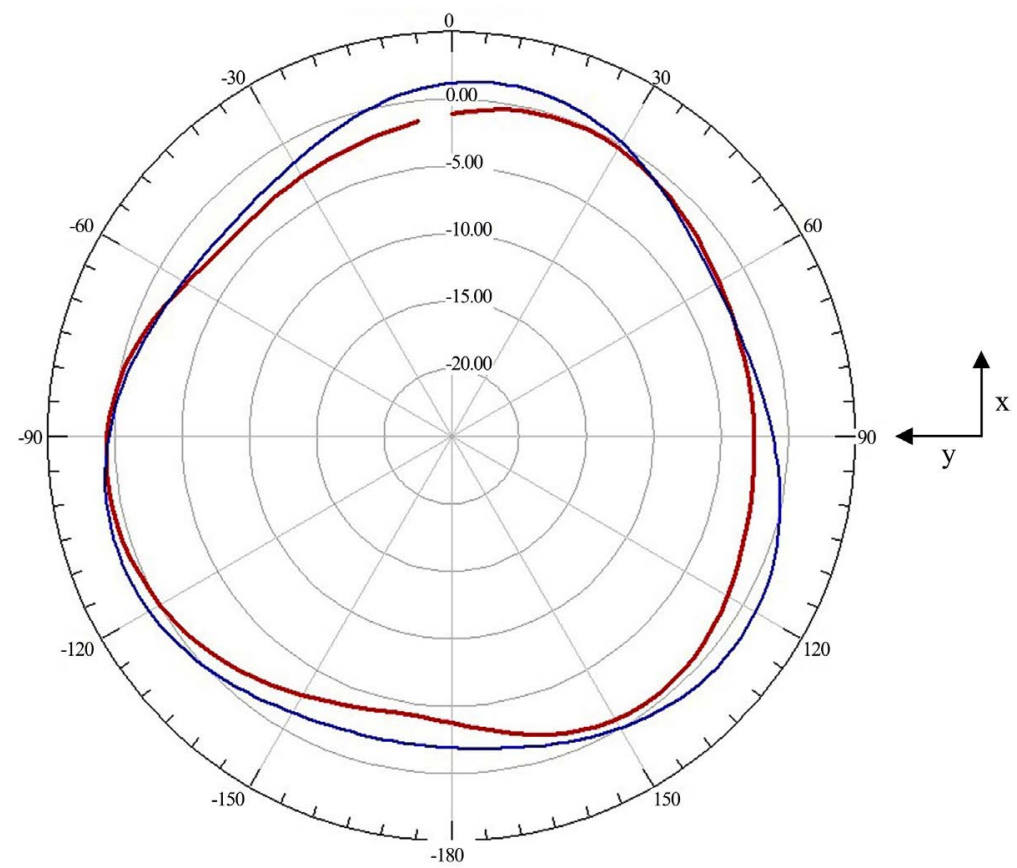

Figure 16. Radiation patterns in the xoz and xoy plane at $3 \mathrm{GHz}$. Simulation in blue and measurement in red.

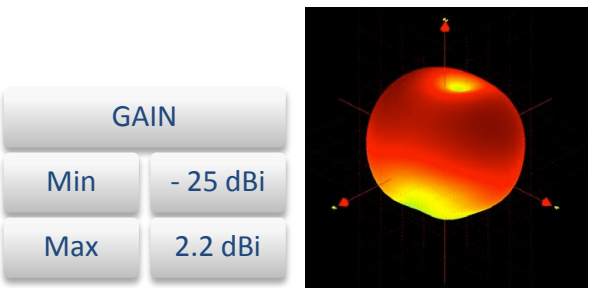

(a)

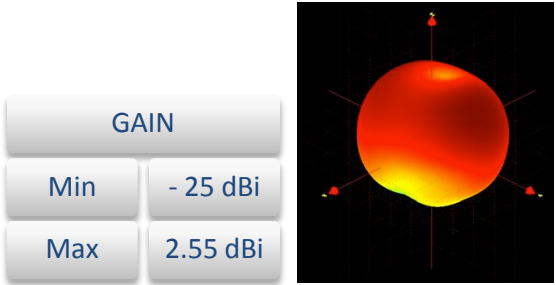

(b)

Figure 17. 3D measured radiation patterns (a) at $3000 \mathrm{MHz}$ and (b) $2860 \mathrm{MHz}$

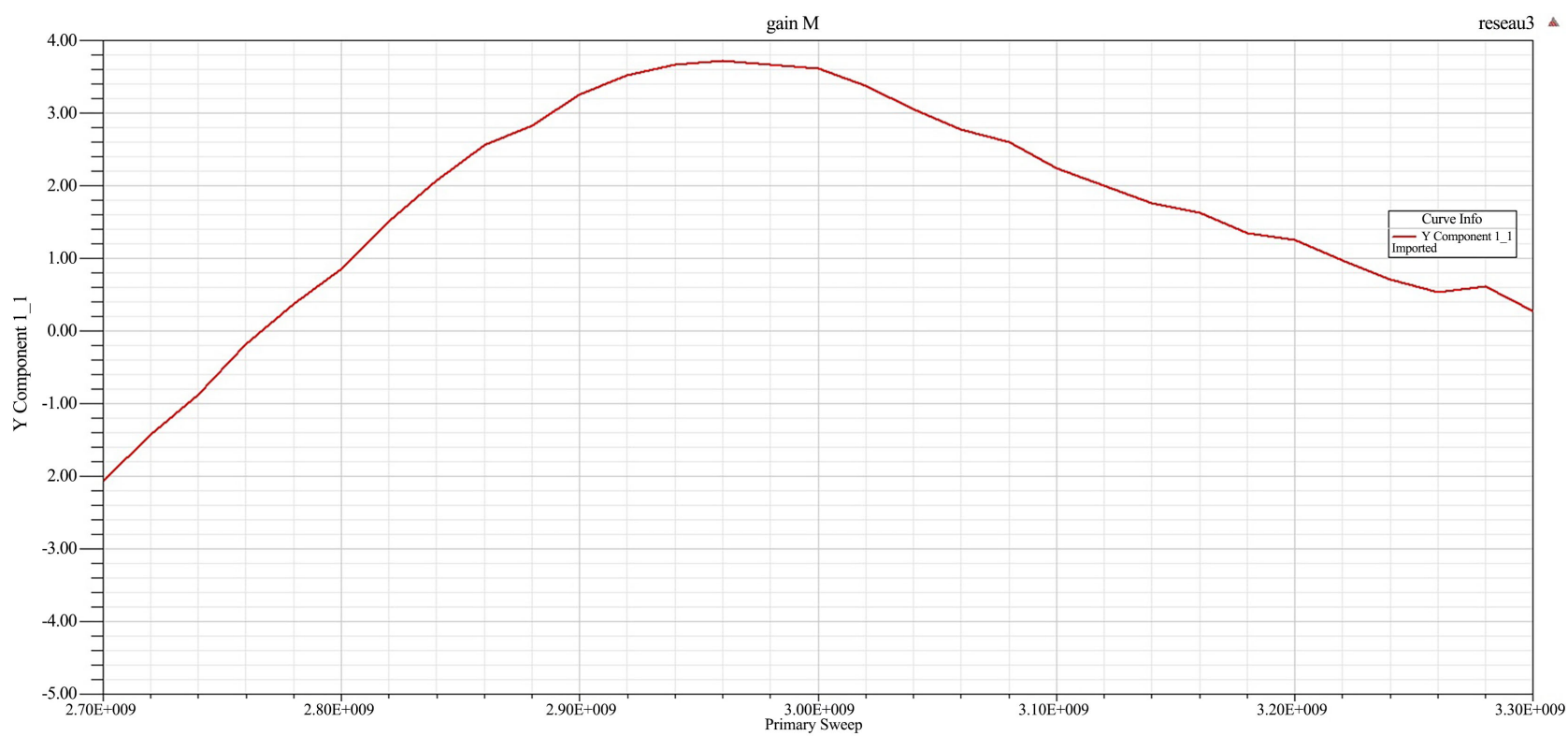

Figure 18. Maximum gain for the 3 dipole array with ground plane. 


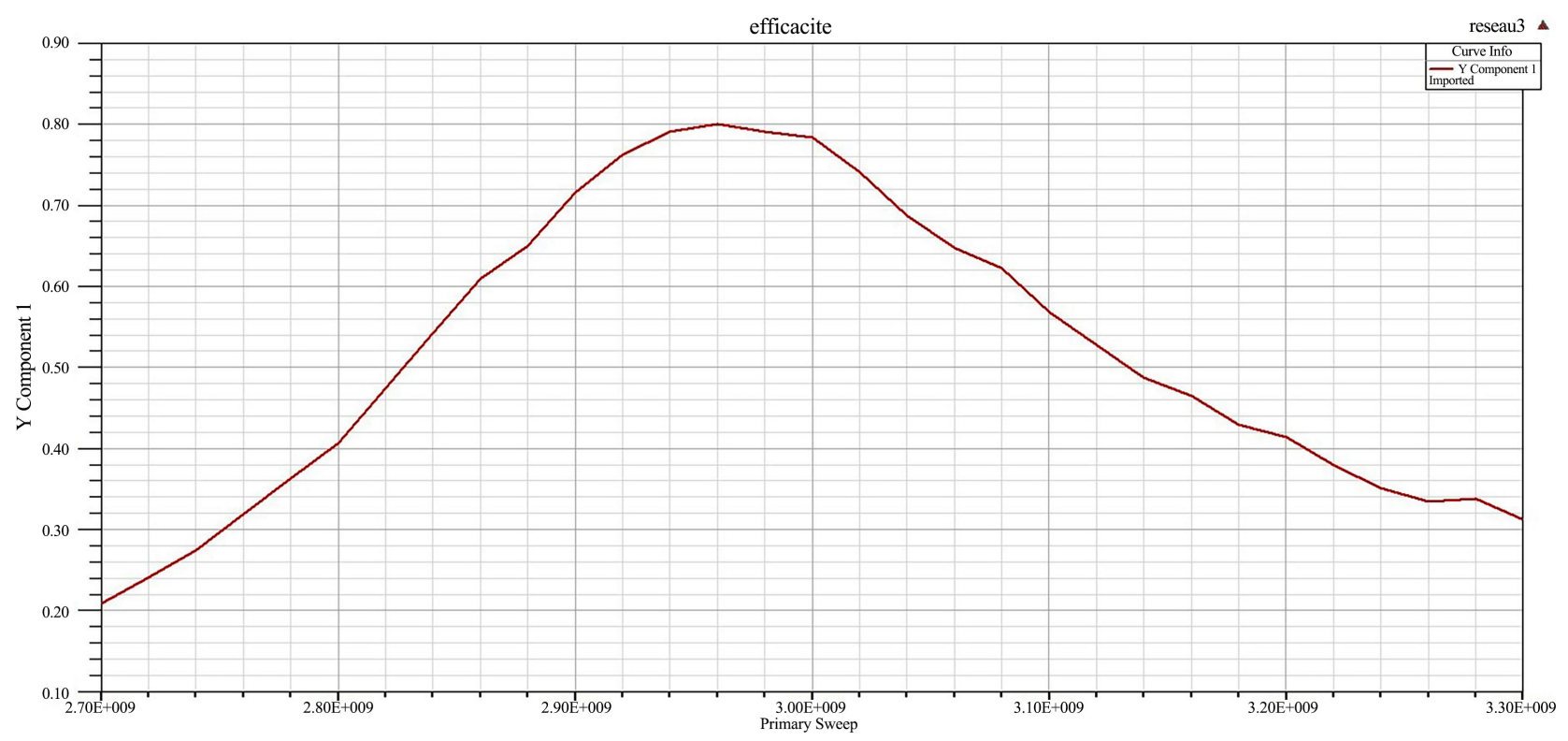

Figure 19. Measured efficiency for the 3 dipole array with ground plane.

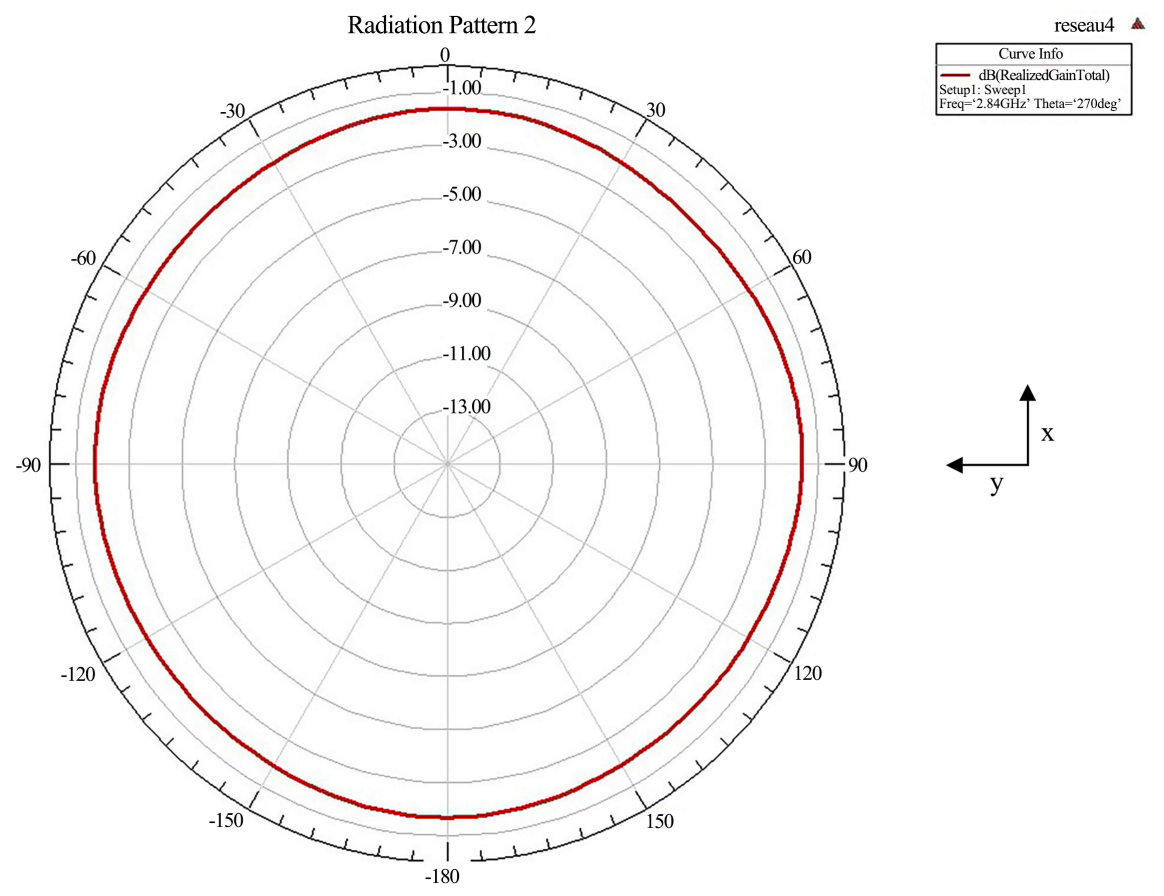

Figure 20. Simulated radiation patterns in the xoy plane at $2.76 \mathrm{GHz}$ for the 4 dipole array with ground plane.

\section{Conclusions}

We present the design of 2 circular dipole arrays in order to obtain omnidirectional radiation pattern with horizontal polarization and stable radiation performances. We obtain good comparison between simulations and measurements.

If we compare the results for the 3 and 4 dipole arrays, The 3-dipole array presents good performances in term of match, bandwidth, gain and efficiency. 
The 4-dipole array presents better performances in term of ripple in the xoy plane. Theses arrays are very compact with a diameter of $60 \mathrm{~mm}$ with a thickness of $0.8 \mathrm{~mm}$. We present in the last section an application for compact base station with no degradation in the performances (we introduce a ground plane at 20 $\mathrm{mm}$ from the array). The choice is now a question of applications. The potential application of these dipole arrays is compact base station for communication systems and antenna for communication for rotating machine.

\section{Conflicts of Interest}

The author declares no conflicts of interest regarding the publication of this paper.

\section{References}

[1] Floc'h, J.M. and Rmili, H. (2006) Design of Multiprinted Dipole Antennas Using Parasitic Elements. Microwave and Optical Technology Letters, 48, 1639-1645. https://doi.org/10.1002/mop.21714

[2] Floc'h, J.-M., El Sayed Ahmad, A., Denoual, J.M. and Rmili, H. (2012) Design of Printed Dipole Antenna with Reflector and Multi-Directors. IRECAP, 2.

[3] Floc'h, J.-M., El Sayed Ahmad, A., Tarot, A.C., Loison, R., Thizon, S. and Daden, J.-Y. (2012) On the Design of Planar Printed Dipole Array Antennas. Wireless Engineering and Technology, 3, 203-209. https://doi.org/10.4236/wet.2012.34029

[4] Wong, K.-L., Hsiao, F.-R. and Chiou, T.-W. (2004) Omnidirectional Planar Dipole Array Antenna. IEEE Transactions on Antennas and Propagation, 52, 624-628. https://doi.org/10.1109/TAP.2004.823897

[5] Morrow, J.D. (2003) Polarization-Adjustable Omnidirectional Dipole Array. IEEE Antennas and Wireless Propagation Letters, 2, 223-225. https://doi.org/10.1109/LAWP.2003.819662

[6] Phongcharoenpanich, C., Polkaew, W., Luadang, B. and Akkaraekthalin, P. (2015) A Horizontally Polarized Omnidirectional Antenna Using Stacked Curve Dipoles for DTV Reception. International Journal of Antennas and Propagation, 2015, Article ID 107148. https://doi.org/10.1155/2015/107148 